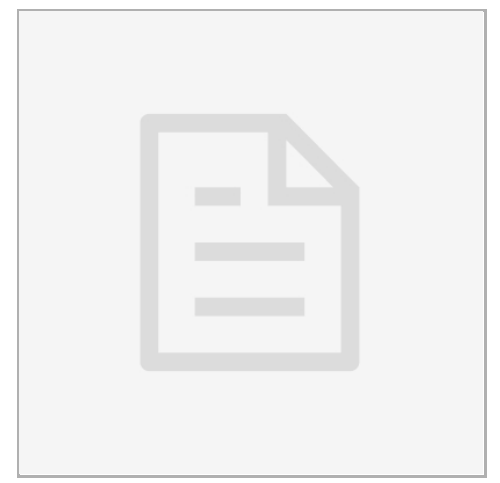

JUN 29, 2021

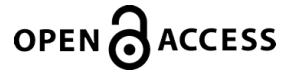

DOI:

dx.doi.org/10.17504/protocol s.io. 62 dhga 6

Protocol Citation: Pi-Hua Chang, Ching-Rong Lin, YunHsiang Lee, Yi-Lin Liu, GeeChen Chang, Yeur-Hur Lai, PiHua Chang, Taichung Veterans General Hospital 2021. Exercise experiences in patients with lung cancer patients: A qualitative approach. protocols.io https://dx.doi.org/10.17504/p rotocols.io.62dhga6

\section{MANUSCRIPT CITATION:}

Exercise experiences in patients with metastatic lung cancer: A qualitative approach

License: This is an open access protocol distributed under the terms of the Creative Commons Attribution License, which permits unrestricted use, distribution, and reproduction in any medium, provided the original author and source are credited

Protocol status: Working We use this protocol and it's working

Created: Sep 02, 2019

\title{
(3) Exercise experiences in patients with lung cancer patients: A qualitative approach
}

Ching-Rong

Pi-Hua Chang ${ }^{1}$, Lin $^{2}$,

Gee-Chen

Chang ${ }^{4}$,

Taichung Veterans General Hospital ${ }^{3}$

${ }^{1}$ Department of Nursing, Taichung Veterans General Hospital, 1650

Taiwan Boulevard Sect. 4, Taichung, Taiwan 40705, ROC;

2School of Nursing, College of Medicine, Chang Gung University, No.259,

Wenhua 1st Rd., Guishan Dist., Taoyuan City 33302, Taiwan, ROC;

${ }^{3}$ School of Nursing, College of Medicine, National Taiwan University (NTU),

1 Jen-Ai Rd., Sec. 1 Taipei, 100, Taiwan, ROC;

${ }^{4}$ Division of Chest Medicine, Department of Internal Medicine, and

Comprehensive Cancer Center, Taichung Veterans General Hospital, 1650

Taiwan Boulevard Sect. 4, Taichung, Taiwan 40705, ROC

Pi-Hua Chang 
Last Modified: Jun 29, 2021

PROTOCOL integer ID: 27429

Keywords: Metastatic lung cancer, exercise experiences, qualitative approach, narrative interview
ABSTRACT

Background Patients with metastatic lung cancer have a series of symptoms and many severe treatment-related side effects. However, little evidence is in support of benefits in performing exercise during their hospitalization. The purpose of this study was to understand exercise experiences inpatients with metastatic lung cancer.

Methods A qualitative approach with face-to-face in-depth interview was conducted at an inpatient ward of a medical center in central Taiwan, on 24 recruited participants with metastatic lung cancer. The interview transcripts went through a narrative analysis by a group of qualitative research experts to extract and validate the main themes.

Results Three primary themes were identified: (a) modifying exercise to maximize physical functions, (b) living with symptoms and frustration but continuing exercise, and (c) doing exercise to sustain hopes, inner power, and life. Two secondary findings were: (a) most participants adopted walking as their main form of exercise because of its flexibility, and (b)participants, according to the severity of their symptoms, adjusted their exercise towards shorter time durations and shorter distances, slower speeds, and higher frequencies.

Conclusions Participants with metastatic lung cancer adjusted their exercise behaviors to balance disease and treatment-induced deteriorations and to boost themselves to fight cancer and sustain survival. Individualized exercise schemes should be adopted in clinical practice to enhance their physical functions and life meaning. Such a home-based rehabilitation program in exercise was acceptable to most participants with metastatic lung cancer, including improvements in physical fitness, motivation, and the ability to manage symptoms.

\section{GUIDELINES}

We used a narrative-based qualitative approach with open-ended interviews to explore exercise experiences of our patients. The narrative analysis is an effective way to understand less structured, yet rich and in-depth descriptions from interviews regarding complex and subjective experiences, such as thoughts, feelings, and meanings. This method has been applied to study cancer patients and their exercise behaviors. Specifically, it was used to explore the rationale underlying timespent on exercise, and on exercise per se. Analyzing narratives from interviews of these patients can reveal the various reasonings, and different information regarding the way patients live with cancer, and can also help to develop more patientcentered care.

\section{MATERIALS}

Interview guide 


\begin{tabular}{||l|l|}
\hline No. & $\begin{array}{l}\text { Questions } \\
\text { Q. }\end{array}$ \\
\hline $\begin{array}{l}\text { Can you talk } \\
\text { about your } \\
\text { thoughts } \\
\text { and } \\
\text { experiences } \\
\text { on exercise? }\end{array}$ \\
\hline $\begin{array}{l}\text { How did you } \\
\text { feel about } \\
\text { exercise } \\
\text { before and } \\
\text { after the } \\
\text { diagnosis of } \\
\text { lung cancer? }\end{array}$ \\
\hline $\begin{array}{l}\text { Can you talk } \\
\text { about the } \\
\text { exercise you } \\
\text { take in daily } \\
\text { life and how } \\
\text { do you do it? }\end{array}$ \\
\hline $\begin{array}{l}\text { What are } \\
\text { your } \\
\text { thoughts or } \\
\text { opinions } \\
\text { about } \\
\text { exercise? }\end{array}$ \\
\hline $\begin{array}{l}\text { How did you } \\
\text { adjust your } \\
\text { exercise } \\
\text { behaviors in } \\
\text { response to } \\
\text { various } \\
\text { physical or } \\
\text { psychologica } \\
\text { conditions? }\end{array}$ \\
\hline $\begin{array}{l}\text { How did } \\
\text { you adjust or } \\
\text { modify your } \\
\text { exercise } \\
\text { behaviors in } \\
\text { different } \\
\text { situations? }\end{array}$ \\
\hline $\begin{array}{l}\text { Can } \\
\text { you talk } \\
\text { about how } \\
\text { you changed } \\
\text { your } \\
\text { exercise } \\
\text { behaviors in } \\
\text { your } \\
\text { situations? } \\
\text { Wou continue } \\
\text { or stop } \\
\text { doing } \\
\text { exercise? }\end{array}$ \\
\hline
\end{tabular}


(.) If participants had any problems during interviews, the author would deal with participants' conditions and comfort participants' emotions immediately in the hospital.

\section{BEFORE START INSTRUCTIONS}

The study setting is at an internal chest ward with 52 beds housed in a medical center with 1,500 beds in central Taiwan. This ward is specialized in caring adults with respiratory problems (lung and breathing) in which about $60 \%$ of them are lung cancer. Here, an average of two to three hospitalized patients/week with metastatic lung cancer has received diagnostic examinations, treatments, symptom management, or palliative care.

1 A purposeful sampling was used to collect the diversity of exercise experiences in our participants.

2 The inclusion criteria were as follows: (1) older than age 20 years; (2) diagnosed with metastatic lung cancer; (3) spoke Chinese or Taiwanese; (4) had exercise habits or behaviors; (5) admitted in our hospital; and (6) understood the research purpose and agreed to participate in the study.

3 The exclusion criteria were as follows: (1)diagnosed lung cancer with stage I IIIB; (2) not admitted in our hospital; (3) never did exercise before and after cancer diagnosis; (4) refused to participate in the study, (5) declined to audio-recording the interview, and (6) physical conditions were too sick to talk.

4 The ethical approval of this qualitative study was obtained from the Institutional Review Board of Taichung Veterans General Hospital, Taiwan (Certificate of approval: C10188). The informed consent was written version.

5 Each participant was interviewed face-to-face by a trained researcher. One of the authors had approached the eligible inpatients and explained to them the purpose and procedures of this study. After obtaining their written informed consent, background information of each participant was recorded and an interview was scheduled.

6 The background information included the following: (a) information of demography (age, sex, marital status), and (b) disease and treatment-related information, including diagnosis time, 
metastasis sites, current cancer treatments, and the score of performance in ECOG (Eastern Cooperative Oncology Group).

7 Methods of data collection were in compliance with the principles of narrative interviews. A quiet and comfortable interview room provided a peaceful and trustful ambiance for interviewing with participants and relative members.

8 Participants had agreed to share their experiences of taking exercise before, after cancer diagnosis of lung cancer and during the metastatic stage.

9 For those who had agreed to participate in the study, the interview began with the following question: 'can you talk about your thoughts and experiences on exercise?' in accordance with an interview guide.

10 All interviews were audio-recorded and transcribed within 48 hours. Transcriptions were all deidentified using codes and stored electronically for analyses.

11 three authors were assigned to independently read, repeatedly reflect, constantly compare cancer- and exercise-related words, sentences and situations, and collaboratively discuss narratives to identify the findings consistent with participants' experiences and semantic expressions.

12 The themes were constructed based on the data validation feature in the Excel software (Microsoft, 2016 version). 